\title{
$7 \quad$ Effect of renewable energy policies on the components' exports from Asian countries
}

\author{
Evidence from the trade of \\ $\mathrm{PV} /$ wind energy with matching \\ econometrics
}

Yasuhiro Ogura

\section{Introduction}

We have seen the global deployment of renewable energy (RE) in the past decade, as seen in the global diffusion of solar photovoltaics (PV), and wind energy. RE has been a part of the climate change mitigation strategy (Stokes, 2016), as it is believed to have considerable potential (IRENA, 2019). Furthermore, the strategy might be intended to tackle the issue of energy security, which evokes the need for less dependence on fossil fuel, especially in countries with scarcity of such energy sources (Fuentes et al., 2020). The vulnerability of the incumbent energy system might also be among the factors affecting the penetration of RE (Mathews and Reinert, 2014), while it has been considered to solve the scarcity of fossil fuel (Pidgeon et al., 2008).

In response, an increasing number of countries perceive RE industry as a new engine of economic growth (Mori and Takehara, 2018). Economic concerns might also have played a role in the penetration of RE (Song, 2015). Organisation for Economic Co-operation and Development (OECD) has set the "green growth" as the agenda for attaining mitigation of climate change or sustainability and the economic growth simultaneously, and RE is placed in "environmental industry" (Jänicke, 2012) that can generate increasing returns (Mathews, 2012).

Owing to the scale economy in production, the global market is dominated by the top ten companies. In wind turbine, Chinese manufacturers account for one-third, followed by other-country manufacturers-Vestas, Siemens, and General Electrics. In solar PV, those in China account for $75 \%$, followed by Korea and Malaysia (REN21, 2020). Accordingly, trade of $\mathrm{RE}$ has rapidly grown in this decade (Figures 7.1a and 7.1b), which also indicates that Asian countries have also become the main exporter in the world PV and wind energy components market. This trend might have also 
been affected by the growing demand from policies mainly in importing countries, for example, European Union (EU) nations and United States.

During the process, promoting policies, for example, FiT and RPS, have been key to the vast diffusion, as they are in force in an increasing number of countries and regions (Olmos et al., 2012; Smith and Urpelainen, 2013; Shrimali et al., 2015). The trade dispute on RE products between the EU and China shows the significant effect of the policy on demand for the components (Bougette and Charlier, 2018).

RE has been vastly disseminated in the past few decades, as a result of promoting policies such as FiT and RPS. Accordingly, Asian manufacturers of PV and wind energy components have rapidly increased their production. The manufacturers in Asian countries have enhanced the export performance with the growing demand for their products, whereas those in EU with RE policies have dominated the global market. The background suggests that RE policies can impact the overall trade, that is, both export and import of PV and wind energy components. Nevertheless, a limited number of empirical studies on the effect of policies in importing countries exist,

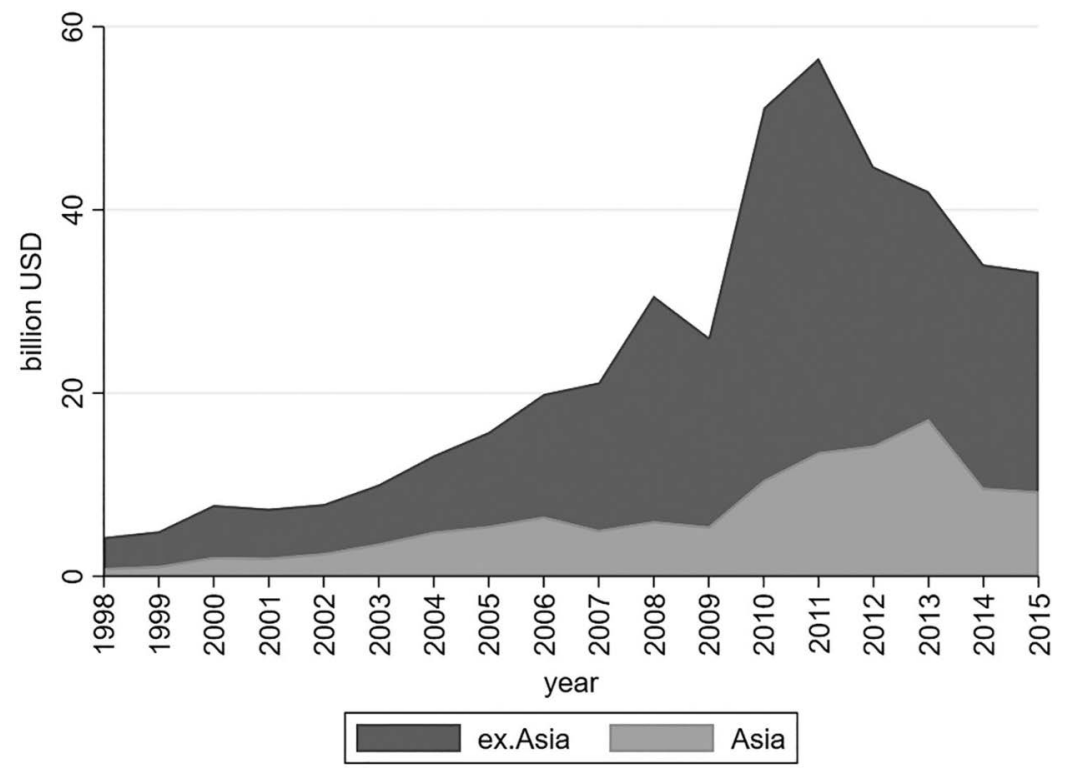

Figure 7.1a Export value and destination of PV components from selected Asian countries: 1998-2015 (CEPII, 2019).

Note: Asian countries: China, India, Indonesia, Japan, Malaysia, South Korea, Thailand (Table 7.A.2). 


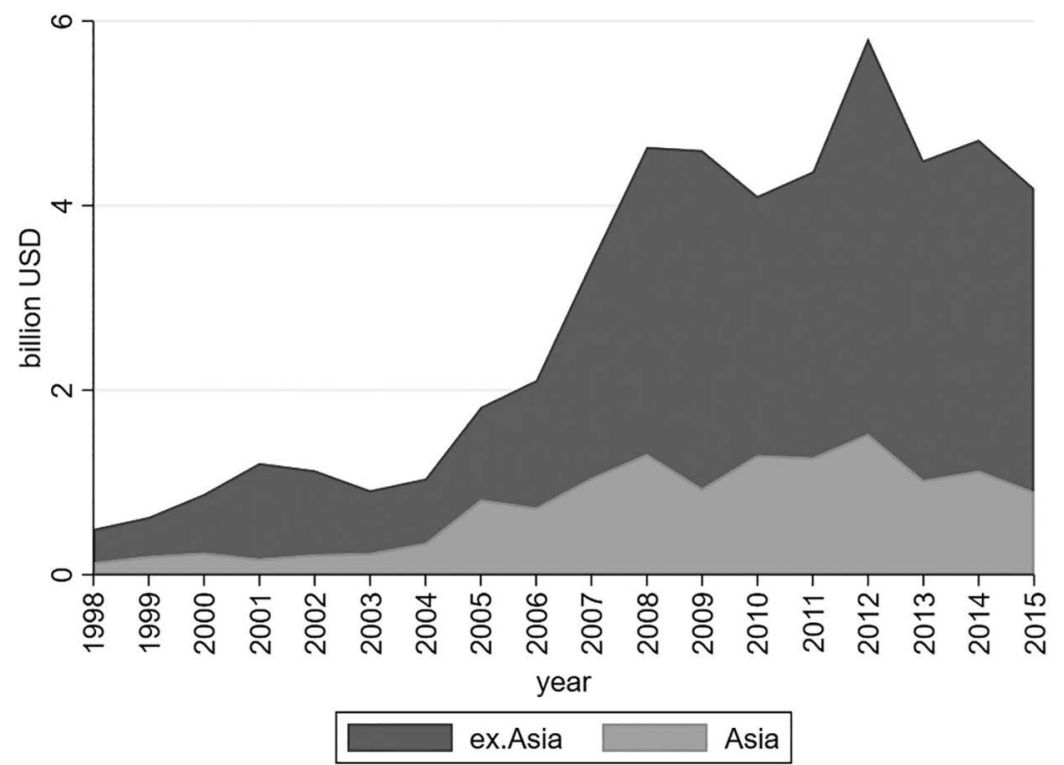

Figure 7.1b Export value and destination of PV/wind energy components from selected Asian countries: 1998-2015 (CEPII, 2019).

Note: Asian countries: China, India, Indonesia, Japan, Malaysia, South Korea, Thailand (Table 7.A.2).

although the literature on the trade of RE components has mainly focused only on those in exporting countries.

Against this backdrop, this chapter analyzes the effect of FiT and RPS on the exports of solar PV and wind energy components from selected Asian countries as the two types of policies have been widely disseminated. We specify and compare the effect of those policies in both exporting and importing countries. Policy dummies are set for each if FiT or RPS had been in force during the periods of the study. In addition to the standard estimation methods in the literature, we apply matching econometrics to control the confounding, that is, mixed effect between gross domestic products (GDP), innovative capacity, and RE policies, in the estimation of the treatment effect of RE policies on PV and wind components' exports.

Section 2 reviews the theoretical and empirical implications on the relationship between RE policy and the exports of PV and wind energy components, and Section 3 specifies the estimated model and the methodology in this chapter. Section 4 shows the estimation results of the standard and matching estimation. Section 5 discusses the estimation results and the 
implication on the potential carbon halo effect. Section 6 concludes this chapter.

\section{Literature review}

RE policies such as FiT and RPS can theoretically increase the profit for producers, and they can be incentivized for technological development if they perceive to gain certain level of surplus. The technological development can also benefit the producers. Price-based policies, such as FiT, can provide more incentives to producers, because the surplus from the policy and technological development is basically distributed to themselves. Conversely, the incentives by quantity-based policy may be limited, as the surplus is mainly distributed to consumers or taxpayers (Menanteau et al., 2003). If the additional profit can lead to the increase in the export of the producers, RE policies may enhance the export competitiveness, as suggested by the Porter hypothesis (Porter and van der Linde, 1995).

Additionally, the rent is also available for overseas manufacturers with a higher price level compared to the world market, which might attract the manufacturers to export to countries where the policies are in force. In this case, the manufacturers in countries with the policies in force may be incentivized to supply more to their home countries than exports. Then, the countries with these policies may increase their relative imports of RE components (Ogura, 2020).

The empirical literature on environmental goods (EGs) trade has applied the gravity model for the analyses on the effect of RE policies on the exports (Costantini and Mazzanti, 2012; Costantini and Crespi, 2013; Groba, 2014). In accordance with previous research, this chapter applies the gravity model in international trade.

$$
T_{i j t}=\alpha_{0} Y_{i t}^{\alpha_{1}} Y_{j t}^{\alpha_{2}} D_{i j}^{\alpha_{3}}
$$

In the basic form devised by Tinbergen (1962), Tijt $_{\text {denotes the trade between }}$ country ${ }_{i}$ and ${ }_{j}$ in year ${ }_{t}$. GDP by ${ }_{i}$ and ${ }_{j}$ in $_{t}$ are expressed with ${ }_{Y i t}$ and $Y j t$, respectively. Last, Dij denotes the physical distance between the two. Hence, equation 7.1 shows that the trade between country ${ }_{i}$ and ${ }_{j}$ can be explained using the economic scale and the distance. GDP is assumed to have a positive association with the trade, while the distance can be thought to be the cost factor, that is, a negative effect. The equation has been widely used to analyze the effect of trade policies (e.g., Rose, 2004; Baier and Bergstrand, 2007) ever since its theoretical foundation has been confirmed (Anderson, 1979). The literature on the gravity model of international trade indicates the considerable effect of the factors omitted in the model. To deal with the problem, Anderson and van Wincoop (2003) argue that the fixed effects of an exporter, importer, and year have to be considered. 
Based on the Porter hypothesis (Porter and van der Linde, 1995), the empirical analyses on EGs trade have examined the relationship of the trade with innovative capacity and environmental policies (e.g., Costantini and Mazzanti, 2012). The model is also applied for the analyses on the effect of RE policies on exports (e.g., Costantini and Crespi, 2013). Among these studies, the duration of FiT is positively associated with the exports, while RPS shows no significant relation (Groba, 2014).

However, the literature has not dealt with the drawbacks. Previous analyses on the trade of EGs and RE components have not considered the theoretical implication on the policy effect, as they assume the positive policy effect on the export based on the Porter hypothesis. Moreover, the empirical literature on the effect of policies in importing countries is limited, while the theoretical implication indicates that the exports can be affected by RE policies in both exporting and importing countries; only Groba and Cao have examined the effect of policies in importing countries as the factors to influence Chinese PV/wind components exports (Groba and Cao, 2014). Furthermore, the literature on the effectiveness of those policies points out the correlation to the innovation (Johnstone et al., 2010), which suggests the potential confounding, that is, mixed effects of GDP, knowledge stock, and RE policies. However, the literature on EGs trade has not yet considered the effect.

\section{Methodology}

\subsection{Standard gravity model}

Based on the literature and challenges reviewed in Section 2, we estimate the effect of FiT and RPS on the exports of PV and wind energy components with the model below. Considering the drawback in the literature in Section 2, this study examines the individual effect of the policy; FiT and RPS in both exporting and importing countries are included in the model individually.

$$
\begin{aligned}
\ln \mathrm{X}_{i j t}= & \alpha 0+\alpha 1 \ln \mathrm{TGDP}_{i j t}+\alpha 2 \ln \mathrm{D}_{i j}+\alpha 3 \ln \mathrm{P}_{i j t}+\alpha 4 \ln \mathrm{K}_{i t}+\alpha 5 \mathrm{REpol}_{i j t} \\
& +d_{i j}+d_{t}+\varepsilon_{i j t}
\end{aligned}
$$

where $\mathrm{X}_{i j t}$ denotes the exports of PV and wind energy components from country $_{i}$ to ${ }_{j}$ in year ${ }_{t}$. Following Anderson and van Wincoop (2003), the model in this study includes exporter/importer/year fixed effects $(d i, d j, d t)$.

Based on the study by Baier and Bergstrand (2009), this chapter examined the effect of the sum of GDP in exporter and importing countries, that is, TGDP $_{i j t}$ in equation 7.3.

$$
\mathrm{TGDP}_{i j t}=\mathrm{Y}_{i t}+\mathrm{Y}_{j t}
$$


As already mentioned earlier, $\mathrm{D}_{i j}$ denotes the distance between exporter and importer. Dummy variables for sharing the common border and common language: $\mathrm{CNTG}_{i j}$ and $\mathrm{LANG}_{i j}$ are also included in the model as the cost components of the bilateral trade. Both dummies are assumed to be positively associated with the exports since the feature is likely to be the higher possibility to the relationship in the trade.

The price effect is also considered in this chapter. The variable $\mathrm{P}_{i j t}$ is calculated with the trade data by equation 7.4. $\mathrm{Q}_{i j t}$ denotes the quantity of traded products annually. Hence, $\mathrm{P}_{i j t}$ is the unit value of the exports from ${ }_{i}$ to $j$.

$$
\mathrm{P}_{i j t}=\mathrm{X}_{i j t} / \mathrm{Q}_{i j t}
$$

This study also considers the effect of innovative capacity following the suggestion of Porter and van der Linde (1995). In reference to Popp et al. (2011), the knowledge stock variable $\mathrm{K}_{i t}$ is calculated by equation 7.5 with patent $\mathrm{PAT}_{i t}$ statistics. This examines the effect on the exports as the proxy for the innovative capacity.

$$
\mathrm{K}^{i t}=\sum_{s=0}^{\infty} e^{-\delta_{1}(s)}\left(1-e^{-\delta_{2}(s+1)}\right) \operatorname{PAT}_{i(t-s)}
$$

\subsection{Matching econometrics in the gravity model}

Matching econometrics has been applied to the gravity model to analyze the treatment effect of trade policies, for example, free trade agreement (FTA) and accession to World Trade Organization (Baier and Bergstrand, 2009; Kohl and Trojanowska, 2015). This might be partly because the omitted variable bias cannot be fully compensated by the inclusion of fixed effects. Furthermore, FTA can be determined not randomly but affected by other factors, for example, economic mass and the similarity of exporters and importers (Baier and Bergstrand, 2009), which shows the considerable effect of confounding. Matching with these standard gravity variables can control the confounding, and the potential bias with the policy variables can be minimized. Therefore, the matching estimator focuses more on the relationship between export and RE policies, whereas the standard gravity model estimation examines the effect of every regressor in the model. Considering potential confounding that has not been examined in the literature on the trade of EGs including RE components, this chapter applies matching estimator in the analysis.

In the application of matching econometrics in the gravity model, we follow the study by Baier and Bergstrand (2009). Regarding the estimation of the average treatment effect (ATE) and the effect on the treated (ATT), they referred to Abadie and Imbens (2006) considering the large sample 
properties and the conditional bias with more than one covariate in the model. Since the model in this study has multiple continuous variables, for example, GDP, distance, knowledge stock, and price variables, we also apply the same nearest neighbor matching with robust estimation, adjusting the bias from covariates. Referring to Baier and Bergstrand (2009), the treatment effect on the exports in the matching is explained as follows:

$$
X_{i}^{*}(0)= \begin{cases}X_{i}, & \text { if } \mathrm{REPol}_{i}=0 \\ \frac{1}{M} \sum j \in J_{M}(i) X_{j}, & \text { if } \mathrm{REPol}_{i}=1\end{cases}
$$

and

$$
X_{i}^{*}(1)= \begin{cases}\frac{1}{M} \sum j \in J_{M}(i) X_{j}, & \text { if } \mathrm{REPol}_{i}=0 \\ X_{i}, & \text { if } \mathrm{REPol}_{i}=1\end{cases}
$$

Also, the ATE and ATT can be expressed as follows:

$$
\begin{aligned}
& A T E_{M}=\frac{1}{N} \sum_{i=1}^{N}\left[X_{i}^{*}(1)-X_{i}^{*}(0)\right] \\
& A T T_{M}=\frac{1}{N} \sum_{R E P o l_{i}=1}\left[X_{i}-X_{i}^{*}(0)\right]
\end{aligned}
$$

Missing outcome (export) is imputed from equations 7.6 and 7.7 in the set of indices for the first ${ }_{M}$ matches, that is, ${ }_{J M}(i)$, based on the index ${ }_{j}$ in the ${ }_{N}$ pairs of the countries. After the process, ATE is estimated with the observation $_{N}$, and the estimators for ATT are obtained only for countries with RE policies in force. Variable REPol $i$ is also applied to the policies in importing countries $\mathrm{REPol}_{j}$, as the heterogeneous policy effect is key in this study. Balanced plots of the matching econometrics are shown in the Appendix.

\subsection{Data}

Trade data (export value and quantity) are extracted from BACI database (CEPII, 2019), and the standard gravity variables, for example, CNTG and LANG, from GeoDist database (CEPII, 2015). Data on GDP are from World Development Indicators database by World Bank (2019). Patent data of the technologies related to PV and wind energy are extracted from OECD statistics (OECD, 2019). The data on the implementation of FiT and RPS are taken from IEA/IRENA (2019).

The period of this study is between 1998 and 2015. A total of 56 countries are examined as they are included in OECD-EPAU (2013), which is listed in the Appendix. For analyzing the trend of exports from Asia, only the 
exports from seven Asian countries ${ }^{1}$ are considered in this study, and the importing countries in this study are 56 countries including seven Asian countries mentioned above (listed in Table 7.A.2). Descriptive statistics is supplied in Appendix (Table 7.A.3).

\section{Results}

\subsection{Results of the standard gravity model}

First, the results of the estimation with the standard gravity model are shown in Tables 7.1 and 7.2. In the tables, subscripts $i$ of FiT and RPS stand for the policies in exporting countries, and subscripts $j$ for those in importing countries.

The result indicates the different effect between FiT and RPS, and between exporting and importing countries. FiT and RPS in exporting countries are negatively associated with the exports of PV components, while the effect is insignificant with fixed effects (columns 5 and 6 in Table 7.1). Conversely, RPS in exporting countries is positively associated with wind component exports in the model with fixed effects (columns 2 and 6 in Table 7.2). Additionally, both FiT and RPS in importing countries indicate their positive effect on the exports of PV and wind energy components (columns 3 and 4 in Tables 7.1 and 7.2).

The positive effect of GDP and the negative effect of bilateral distance are consistent with the assumption in the standard gravity model. The estimation of price effect shows a mixed result, suggesting a positive effect on PV without fixed effects, whereas it shows a negative effect on wind energy components.

Knowledge stock effect is also somewhat mixed. PV export is positively associated with the effect in the estimation with fixed effects. However, the knowledge stock of wind energy is negatively associated with the export (columns 5-8 in Table 7.2). This negative effect of knowledge stock may have been influenced by the stagnation of the exports in 2007-2015 (Figures 7.1a and 7.1b), as no significant effect is detected in the estimation of PV exports. The overall positive effect of knowledge stock is also indicated by Costantini and Mazzanti (2012). Nevertheless, in this study, the robustness of the effect was not seen in the estimation.

\subsection{Results of the matching econometrics}

The results of the estimation with matching econometrics are shown in Table 7.3. Subscripts $i$ and $j$ of FiT and RPS in the tables again denote the policies in exporting and importing countries, respectively.

The results show the opposite effects of exporting and importing countries. In exporting countries, FiT has negative effects, while the ATT of RPS 


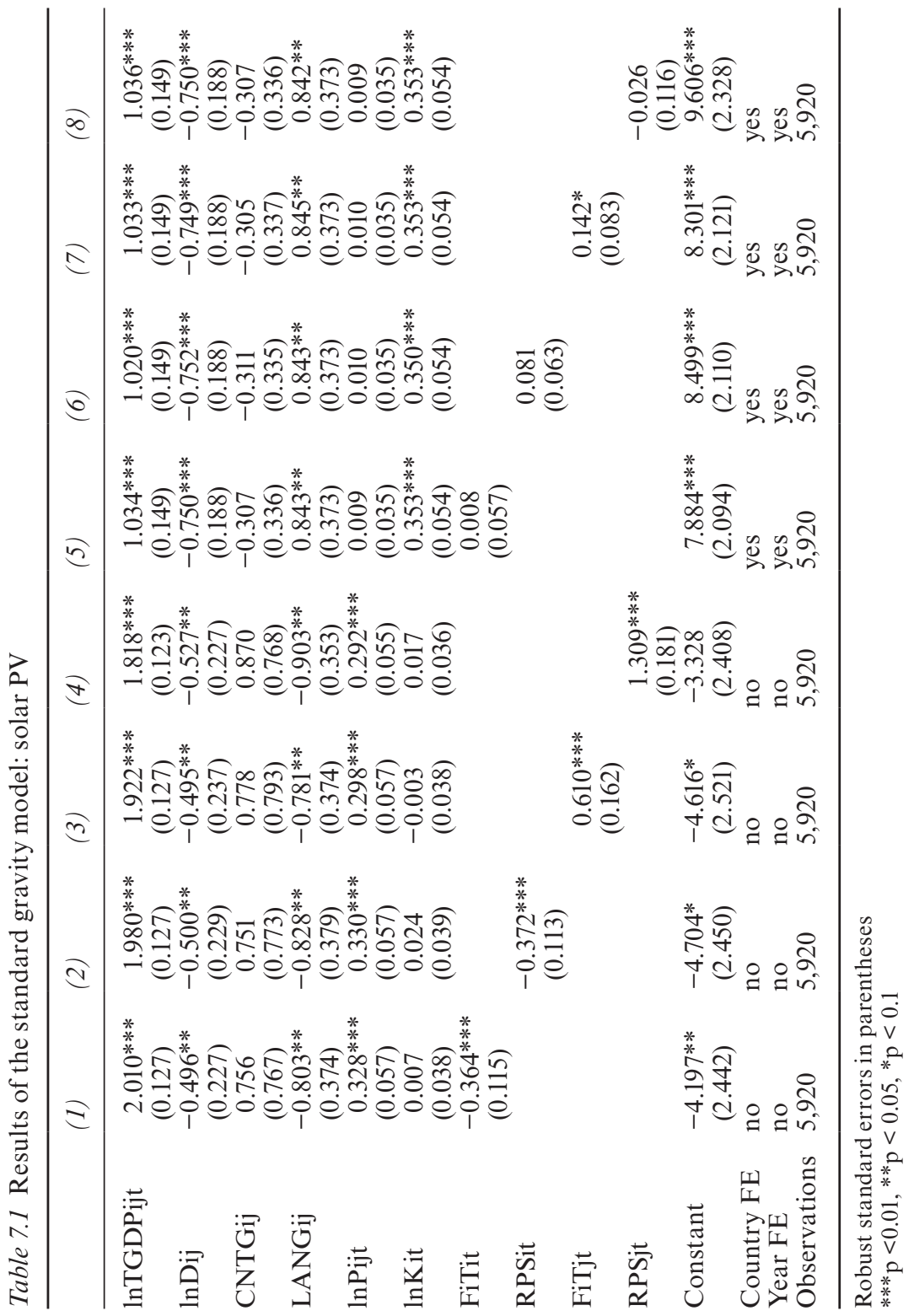




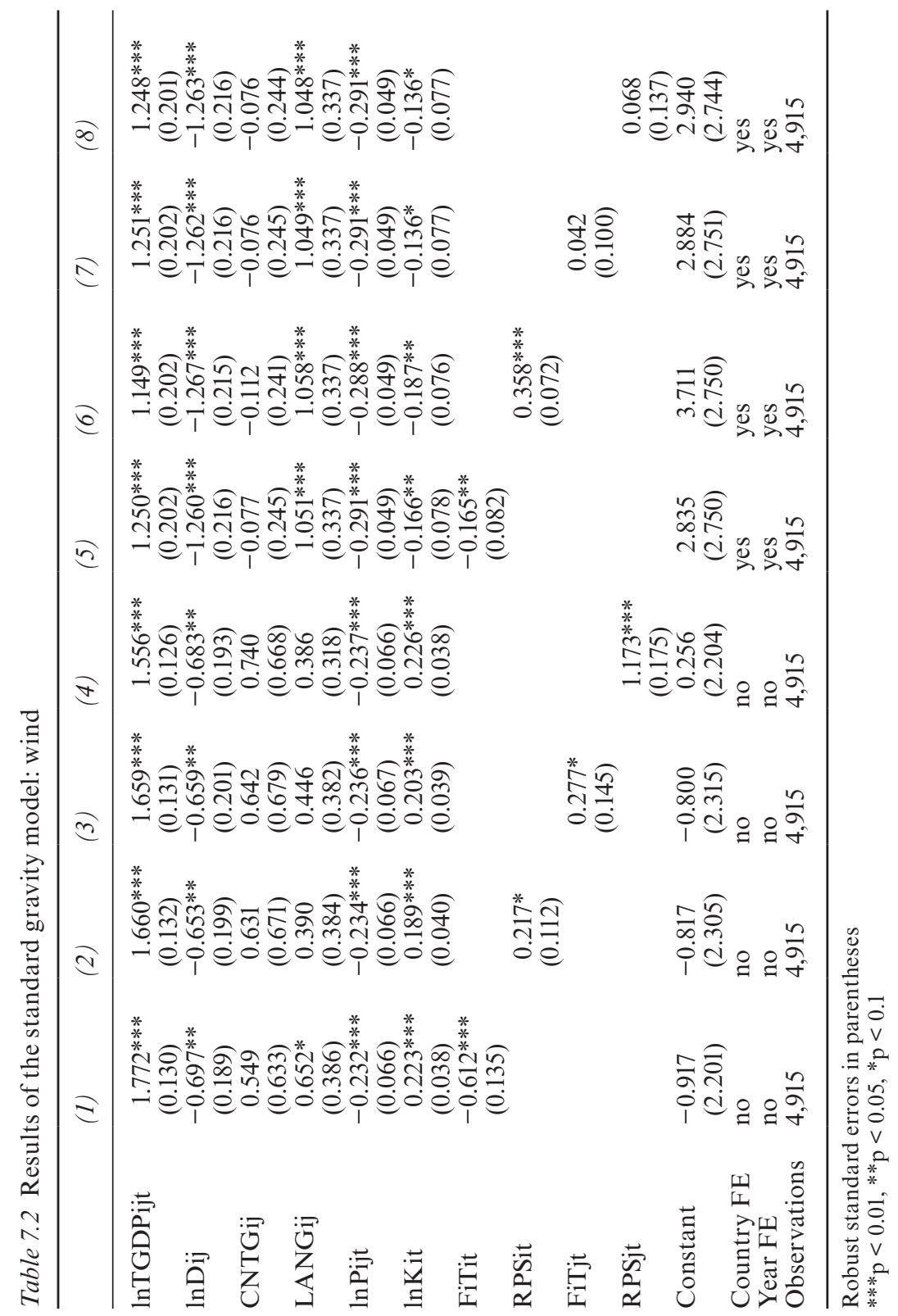


shows weak significance in wind energy. Conversely, both FiT and RPS in importing countries show a positive effect on the export except for insignificant ATE of FiT for wind.

Balance plots of the estimations are displayed in Figures 7.A-1a-7.A-1d and 7.A-2a-7.A-2d in Appendix A.1, which show the density plots of samples before and after matching. As shown in the plots for the continuous variables in the model, price and knowledge stock variables are also included in the estimation to control the effect.

\section{Discussion}

Overall weaker significance of the policy effect in the standard gravity model estimation might have resulted from the mixed effect with potential bias from other factors than RE policies. The results of the matching estimation are more robust, showing the negative effect of policies in exporting countries and the positive effect of policies in importing countries on the exports. These different results between the two estimations may be associated to the effect of the variables other than RE policies. They may generate bias in the standard estimation and make the results unclear.

The negative effect of the policy in exporting countries is contradictory to previous studies (Costantini and Mazzanti, 2012; Groba, 2014). This contradictory result may be because of the policy-induced higher profitability in home countries than in the global market. The higher profitability motivated the manufacturers of PV and wind energy components to prioritize supplying to their home countries (Jaffe and Palmer, 1997). Since FiT sets the unified policy level on the price, FiT in exporting countries might be the clear sign for the manufacturers to supply to those countries.

Table 7.3 ATE and ATT of FiT and RPS on PV/wind energy components' exports

\begin{tabular}{|c|c|c|c|c|c|c|c|c|}
\hline & $P V$ & & & & Wind & & & \\
\hline & FiTit & RPSit & FiTjt & $R P S j t$ & FiTit & RPSit & FiTjt & $R P S j t$ \\
\hline & (1) & (2) & (3) & (4) & (5) & (6) & (7) & (8) \\
\hline ATE & $\begin{array}{c}-0.564 * * * \\
(0.088)\end{array}$ & $\begin{array}{c}-4.352^{* * *} \\
(0.205)\end{array}$ & $\begin{array}{l}0.355^{* * * *} \\
(0.056)\end{array}$ & $\begin{array}{l}1.033^{* * * *} \\
(0.068)\end{array}$ & $\begin{array}{c}-0.688^{* * *} \\
(0.086)\end{array}$ & $\begin{array}{l}-1.265^{* * *} \\
(0.162)\end{array}$ & $\begin{array}{c}0.068 \\
(0.067)\end{array}$ & $\begin{array}{l}0.688 * * * \\
(0.085)\end{array}$ \\
\hline ATT & $\begin{array}{c}-0.697^{* *} \\
(0.105)\end{array}$ & $\begin{array}{c}-0.653^{* *} \\
(0.104)\end{array}$ & $\begin{array}{c}-0.659^{* *} \\
(0.067)\end{array}$ & $\begin{array}{c}-0.683^{* *} \\
(0.091)\end{array}$ & $\begin{array}{c}-1.260^{* * *} \\
(0.106)\end{array}$ & $\begin{array}{c}-1.267 * * * \\
(0.124)\end{array}$ & $\begin{array}{l}-1.262^{* * * *} \\
(0.081)\end{array}$ & $\begin{array}{l}-1.263^{\text {*** }} \\
(0.106)\end{array}$ \\
\hline Observations & 5,920 & 5,920 & 5,920 & 5,920 & 4,915 & 4,915 & 4,915 & 4,915 \\
\hline
\end{tabular}

Robust standard errors in parentheses

$* * * \mathrm{p}<0.01, * * \mathrm{p}<0.05, * \mathrm{p}<0.1$ 
Nevertheless, the positive effect of FiT and RPS in importing countries is consistent with the results of Groba and Cao (2014), which also seems to be the consequence of the shift in profitability. As foreign manufacturers can obtain the FiT-induced rent, they have been responding to the rent from FiT and RPS (Kwon, 2015), which might have eventually led to more exports to the countries with those policies.

The negative effect of policies in exporting countries and the positive effect of those in importing countries are both consistent with the theoretical implications on the relation between PV and wind energy exports (Ogura, 2020). Therefore, the exports from the selected Asian countries might have fulfilled the growing demand of importing countries with RE policies, and the policies in the Asian countries may have motivated the manufacturers of PV and wind energy components to prioritize supplying to their home countries.

Positive coefficients of price variables in Table 7.1 imply that Asian manufacturers have upgraded quality of the PV components (Wang et al., 2019), while this may be affected merely by the higher price in importing countries caused by the policy effect. In this regard, Asian countries may not necessarily have to offer lower prices to prevail over competition in the global market (Horii, Chapter 8 of this book). In contrast, they are forced to compete in terms of price in the global market of wind energy components, as shown in the negative effect on wind energy in Table 7.2. If the higher price of PV components has resulted merely from the change in the price level by the policy, lower prices can still benefit the manufacturers. However, price competitiveness may not be always beneficial for the manufacturers if the export price reflects the higher quality that is needed in the importing countries.

The upgraded quality of PV components in trade also suggests the shift in the technological capability of Asian countries in the studied period. Positive association between knowledge stock and PV export from Asian countries suggests that the countries have acquired the technology and production capability of PV. If this has been brought by the investment from other countries, Asian countries may have benefited from a part of the carbon halo effect. However, the implementation of FiT and RPS may not lead to the carbon halo effect of the countries, because the growing demand for the components might be fulfilled by the Asian countries' exports rather than the production induced by the investment.

\section{Conclusion}

Global demand for RE has grown in the period with promoting policies, such as FiT and RPS. Accordingly, Asian manufacturers have rapidly increased the production of solar PV and wind energy components. The 
exports of RE components from Asian countries have grown rapidly (Figures 7.1a and 7.1b). The background suggests that Asian countries have played a significant role to meet the growing demand in importing countries with RE promoting policies. However, the past literature on the trade of EGs including RE components has focused mainly on the policy effect of exporting countries. Hence, previous studies have not compared the policy effect between exporting and importing countries.

This chapter analyzes the effect of FiT and RPS in both exporting and importing countries on the export of PV and wind energy components. Furthermore, this study is the first to apply matching to the trade analysis of RE components since previous studies have not controlled the confounding, that is, the mixed effect of regressors in the model.

The estimation results show the contrast between the policies in exporting and importing countries. FiT and RPS in the exporting countries show a negative effect on their exports, which is contradictory to the results in the literature on the trade of EGs (Costantini and Mazzanti, 2012) and PV components (Groba 2014). The results indicate that the manufacturers might have prioritized supplying to the home countries than to exports to others. However, FiT and RPS in importing countries show a positive effect on the exports from Asian countries. This suggests the Asian manufacturers' response to the expansion of their profitability generated by the policies in importing countries.

Contrasting results between the policies in exporting and importing countries in this chapter are consistent with theoretical implications (Ogura, 2020), which have not been clearly considered and examined in the empirical literature on the policy effect on the export of RE components. The results are more robust with matching estimators, which has not been applied in previous studies. Positive effect of the price variable in PV estimation indicates the upgraded quality of the products, which suggests that the mitigation of the effect from the price competition, while the negative effect in wind energy suggests the existence. Therefore, these contrasting results between the exporting and importing countries' policy effect, and between the export price of solar PV and wind energy components, constitute the novelty of this study.

Upgraded quality and positive effect of knowledge effect indicate the growing technological capability of Asian countries on their solar PV manufacturing. If those countries acquire the capability through the investment from other countries, it can be a part of the carbon halo effect, that is, FDIbrought RE technology and production capacity that eventually lead to the export of the components. Conversely, FiT and RPS implementation may not lead to the carbon halo effect, since the growing demand for the components might be fulfilled by the Asian countries' exports. As this chapter has not examined the direct relationship between the investment, the 
deployment of RE, and the shift in the exports of the components, this could be the future scope of research.

\section{Note}

1 China, India, Indonesia, Japan, Malaysia, South Korea, and Thailand.

\section{References}

Abadie, A., G. W. Imbens (2006). Large sample properties of matching estimators for average treatment effects. Econometrica, 74 (1), 235-267, https://doi. org/10.1111/j.1468-0262.2006.00655.x.

Anderson, J. E. (1979). A theoretical foundation for the gravity equation, American Economic Review, 69 (1), 106-116.

Anderson, J. E., E. van Wincoop (2003). Gravity with gravitas: a solution to the border puzzle, American Economic Review, 93 (1), 170-192, https://doi. org/10.1257/000282803321455214.

Baier, S. L., J. H. Bergstrand (2007). Do free trade agreements actually increase members' international trade?, Journal of International Economics, 71 (1), 72-95, https://doi.org/10.1016/j.jinteco.2006.02.005.

Baier, S. L., J. H. Bergstrand (2009). Estimating the effects of free trade agreements on international trade flows using matching econometrics, Journal of International Economics, 77 (1), 63-76, https://doi.org/10.1016/j.jinteco.2008.09.006.

Bougette, P., C. Charlier (2018). Antidumping and feed-in tariffs as good buddies? Modeling the EU-China solar panel dispute, Energy Journal, 39 (6), 171-188, https://doi.org/10.5547/01956574.39.6.pbou.

CEPII (2015). GeoDist, http://www:cepii:fr/CEPII/en/bdd_modele/presentation: asp?id=6. accessed on July 19, 2018.

CEPII (2019). BACI Database, http://www:cepii:fr/CEPII/en/bdd_modele/ presentation:asp?id=1. accessed on August 1, 2019.

Costantini, V., F. Crespi (2013). Public policies for a sustainable energy sector: Regulation, diversity and fostering of innovation, Journal of Evolutionary Economics, 23 (2), 401-429, https://doi.org/10.1007/s00191-010-0211-3.

Costantini, V., M. Mazzanti (2012). On the green and innovative side of trade competitiveness?: The impact of environmental policies and innovation on EU exports, Research Policy, 41 (1), 132-153, https://doi.org/10.1016/j.respol.2011.08.004.

Fuentes, S., R. Villafafila-Robles, P. Olivella-Rosell, J. Rull-Duran, S. GalceranArellano (2020). Transition to a greener Power Sector: Four different scopes on energy security, Renewable Energy Focus, 33 (June), 23-36, https://doi.org/10.1016/ j.ref.2020.03.001.

Groba, F. (2014). Determinants of trade with solar energy technology components: evidence on the porter hypothesis?, Applied Economics, 46 (5), 503-526, https:// doi.org/10.1080/00036846.2013.857005.

Groba, F., J. Cao (2014). Chinese renewable energy technology exports: The role of policy, innovation and markets, Environmental and Resource Economics, 60 (2), 243-283, https://doi.org/10.1007/s10640-014-9766-z. 
IEA/IRENA (2019). Joint Policies and Measures Database, http://www:iea:org/ policiesandmeasures/renewableenergy/. accessed on July 31, 2019.

IRENA (2019). Future of Solar Photovoltaic: Deployment, investment, technology, grid integration and socio-economic aspects, https://www.irena.org/ publications/2019/Nov/Future-of-Solar-Photovoltaic. accessed on December $10,2020$.

Jaffe, A. B., K. Palmer (1997). Environmental regulation and innovation: A panel data study, Review of Economics and Statistics, 79 (4), 610-619, https://doi. org/10.1162/003465397557196.

Jänicke, M. (2012). "Green growth": From a growing eco-industry to economic sustainability, Energy Policy, 48, 13-21, https://doi.org/10.1016/j.enpol. 2012.04.045.

Johnstone, N., I. Haščič, D. Popp (2010). Renewable energy policies and technological innovation: Evidence based on patent counts, Environmental and Resource Economics, 45 (1), 133-155, https://doi.org/10.1007/s10640-009-9309-1.

Kohl, T., S. Trojanowska (2015). Heterogeneous trade agreements, WTO membership and international trade: an analysis using matching econometrics, Applied Economics, 47 (33), 3499-3509, https://doi.org/10.1080/00036846.2015. 1016211.

Kwon, T.-h. (2015). Rent and rent-seeking in renewable energy support policies: Feed-in tariff vs. renewable portfolio standard, Renewable and Sustainable Energy Reviews, 44, 676-681, https://doi.org/10.1016/j.rser.2015.01.036.

Mathews, J. A. (2012). Green growth strategies-Korean initiatives, Futures, 44 (8), 761-769, https://doi.org/10.1016/j.futures.2012.06.002.

Mathews, J. A., E.S. Reinert (2014). Renewables, manufacturing and green growth: Energy strategies based on capturing increasing returns, Futures, 61, 13-22, https://doi.org/10.1016/j.futures.2014.04.011.

Menanteau, P., D. Finon, M. L. Lamy (2003). Prices versus quantities: Choosing policies for promoting the development of renewable energy, Energy Policy, 31 (8), 799-812, https://doi.org/10.1016/S0301-4215(02)00133-7.

Mori, A., M. Takehara (2018). Revisiting china's climate policy: The climate energy conundrum point of view, in China's Climate-Energy Policy: Domestic and International Impacts, edited by A. Mori, chap. 3, Routledge, London, https://doi. org/10.4324/9781351037587-3.

OECD (2019). OECD Statistics, http://stats:oecd:org. accessed on July 20, 2019.

OECD-EPAU (2013). Renewable energy policy dataset, version March 2013, https://www:oecd:org/media/oecdorg/directorates/environmentdirectorate/ 2013-03-04OECD-EPAURenewableEnergyPolicies--FINAL:xls. accessed on September 21, 2018.

Ogura, Y. (2020). Policy as a "porter" of RE component export or import? Evidence from PV/wind energy in OECD and BRICS, Energy Economics, 86, 104,630, https://doi.org/10.1016/j.eneco.2019.104630.

Olmos, L., S. Ruester, S.J. Liong (2012). On the selection of financing instruments to push the development of new technologies: Application to clean energy technologies, Energy Policy, 43, 252-266, https://doi.org/10.1016/j.enpol. 2012.01.001.

Pidgeon, N.F., I. Lorenzoni, W. Poortinga (2008). Climate change or nuclear power-No thanks! A quantitative study of public perceptions and risk framing 
in Britain, Global Environmental Change, 18 (1), 69-85, https://doi.org/10.1016/ j.gloenvcha.2007.09.005.

Popp, D., I. Hašcice, N. Medhi (2011). Technology and the diffusion of renewable energy, Energy Economics, 33 (4), 648-662, https://doi.org/10.1016/ j.eneco.2010.08.007.

Porter, M.E., C. van der Linde (1995). Toward a new conception of the environmentcompetitiveness relationship, Journal of Economic Perspectives, 9 (4), 97-118.

REN21 (2020). Renewables 2020 global status report https://www:ren21:net/reports/ global-status-report/. accessed on February 5th, 2021.

Rose, A. K. (2004). Do we really know that the WTO increases trade?, American Economic Review, 94 (1), 98-114, https://doi.org/10.1257/000282804322970724.

Shrimali, G., G. Chan, S. Jenner, F. Groba, J. Indvik (2015). Evaluating Renewable Portfolio Standards for in-State renewable deployment: Accounting for policy heterogeneity, Economics of Energy \& Environmental Policy, 4 (2), 127-142, https:// doi.org/10.5547/2160-5890.4.2.gshr.

Smith, M.G., J. Urpelainen (2013). The Effect of Feed-in Tariffs on Renewable Electricity Generation: An instrumental variables approach, Environmental and Resource Economics, 1-26, https://doi.org/10.1007/s10640-013-9684-5.

Song, J. (2015). Renewable energy towards green growth, in Green Growth and Low Carbon Development in East Asia, edited by F. Yoshida and A. Mori, chap. 1, Routledge, London, https://doi.org/10.4324/9781315695860.

Stokes, L.C. (2016). Electoral Backlash against Climate Policy: A Natural Experiment on Retrospective Voting and Local Resistance to Public Policy, American Journal of Political Science, 60 (4), 958-974, https://doi.org/10.1111/ ajps.12220.

Tinbergen, J. (1962). Shaping the world economy; Suggestions for an international economic policy, Twentieth Century Fund, New York.

Wang, L., R. Zhuang, S. Huang, Y. Zhao (2019). Quality Competition Versus Price Competition: Why Does China Dominate the Global Solar Photo-Voltaic Market?, Emerging Markets Finance and Trade, 55 (6), 1326-1342, https://doi.org/ 10.1080/1540496X.2018.1507905.

World Bank (2019). World Development Indicators, http://databank:worldbank:org/ data/reports:aspx?source $=$ world-developmentindicators. accessed on August 7, 2019.

Wu, M., J. Salzman (2014). The next generation of trade and environment conflicts: The rise of green industrial policy, Northwestern University Law Review, 108 (2), 401-474.

Yi, H. (2013). Clean energy policies and green jobs: An evaluation of green jobs in U.S. metropolitan areas, Energy Policy, 56, 644-652, https://doi.org/10.1016/ j.enpol.2013.01.034.

\section{A Appendix}

\section{A.1 Balance plot in the matching estimation}

Balance plots are shown in Figures 7.A-1a-7.A-1d and 7.A-2a-7.A-2d as a result of the matching estimation. 


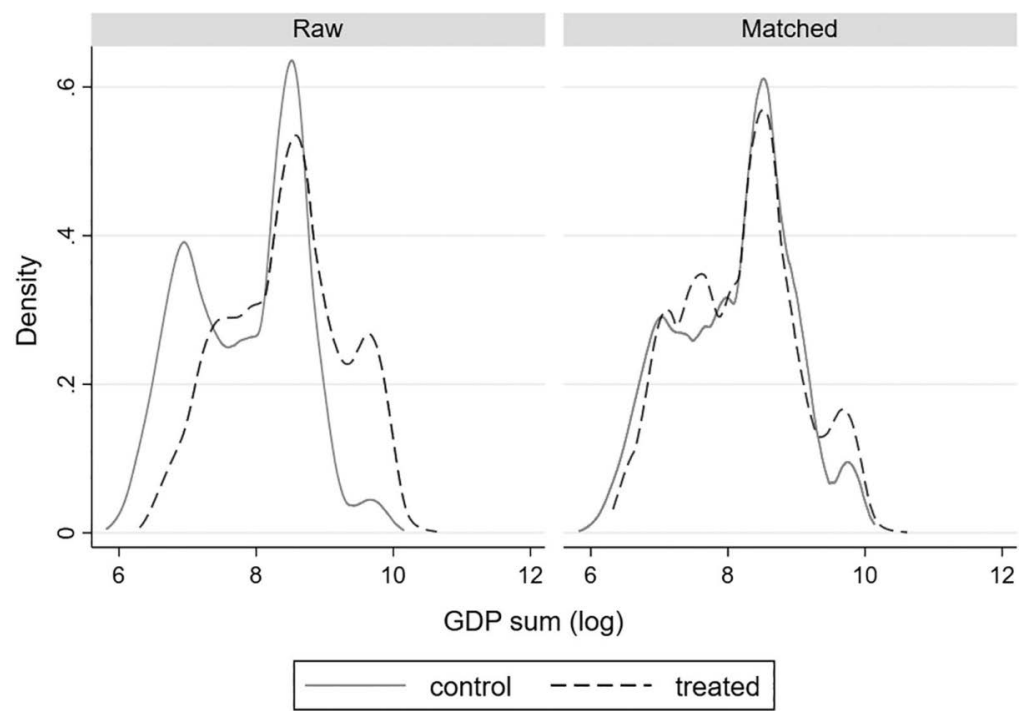

Figure 7. A-1a Balance plot of the sum of exporter and importer GDP: PV.

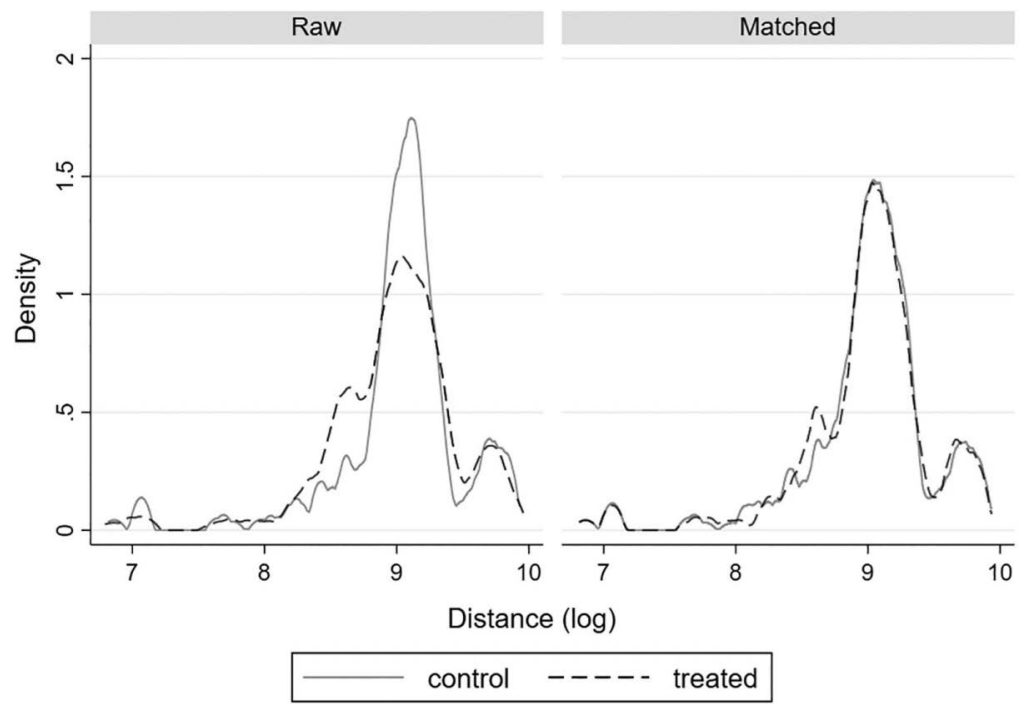

Figure 7.A-1b Balance plot of the distance between exporter and importer countries: PV. 


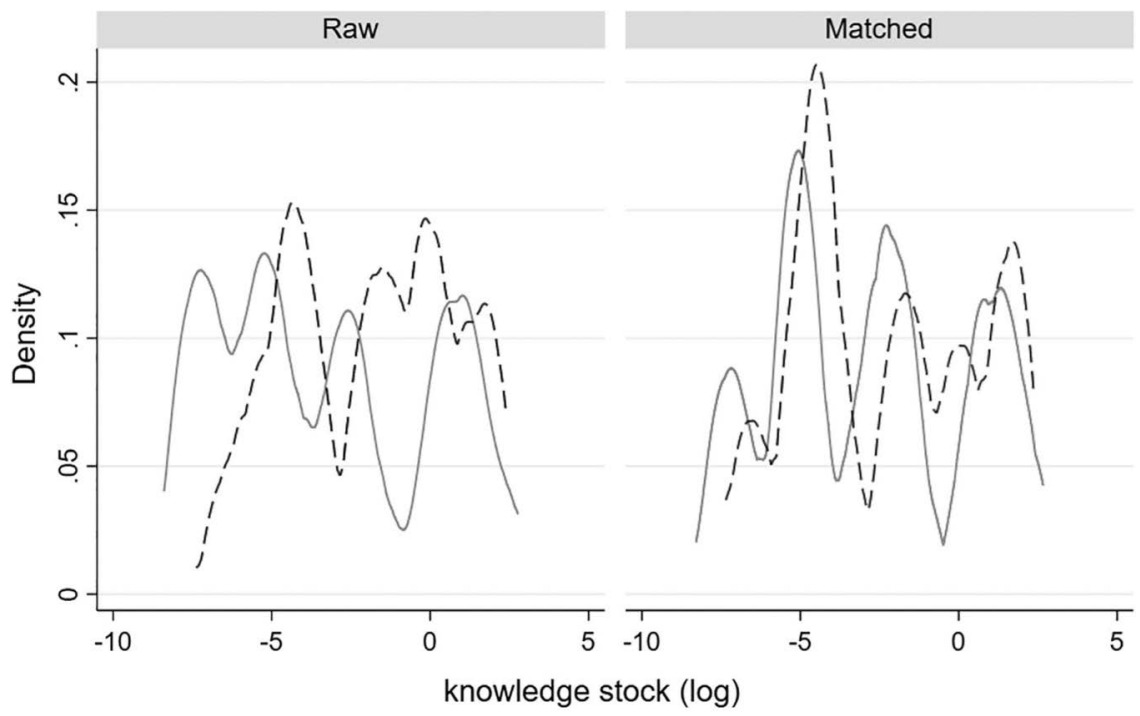

control - - - - treated

Figure 7.A-lc Balance plot of the exporter countries' knowledge stock: PV.
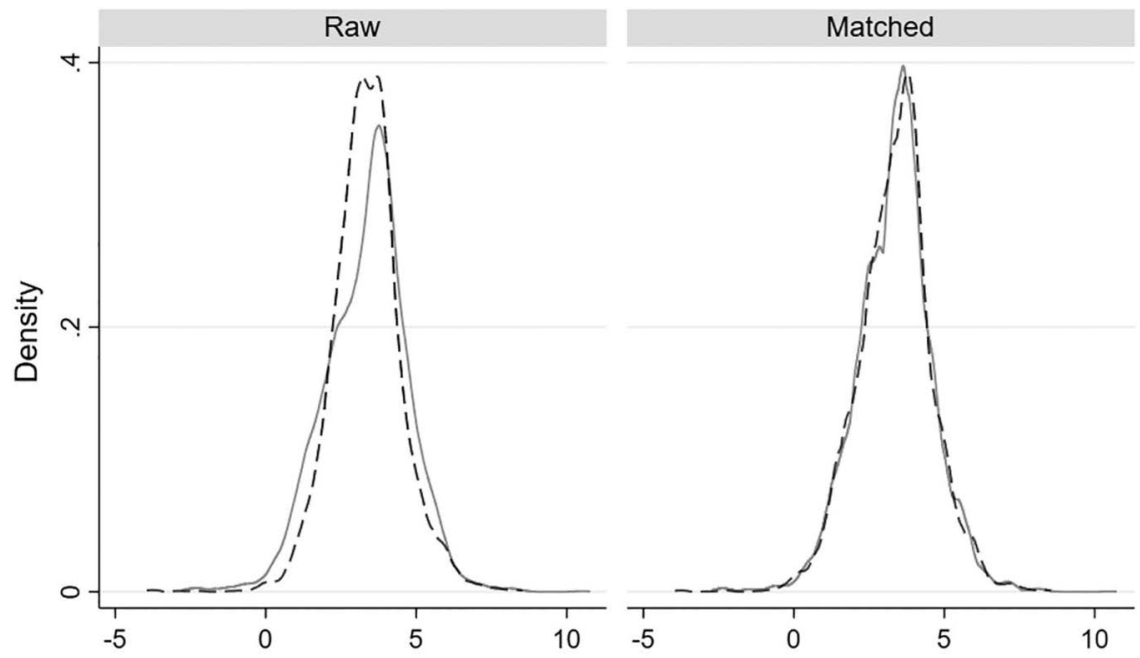

bilateral unit value (log)

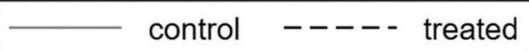

Figure 7.A-1d Balance plot of the bilateral unit value: PV. 


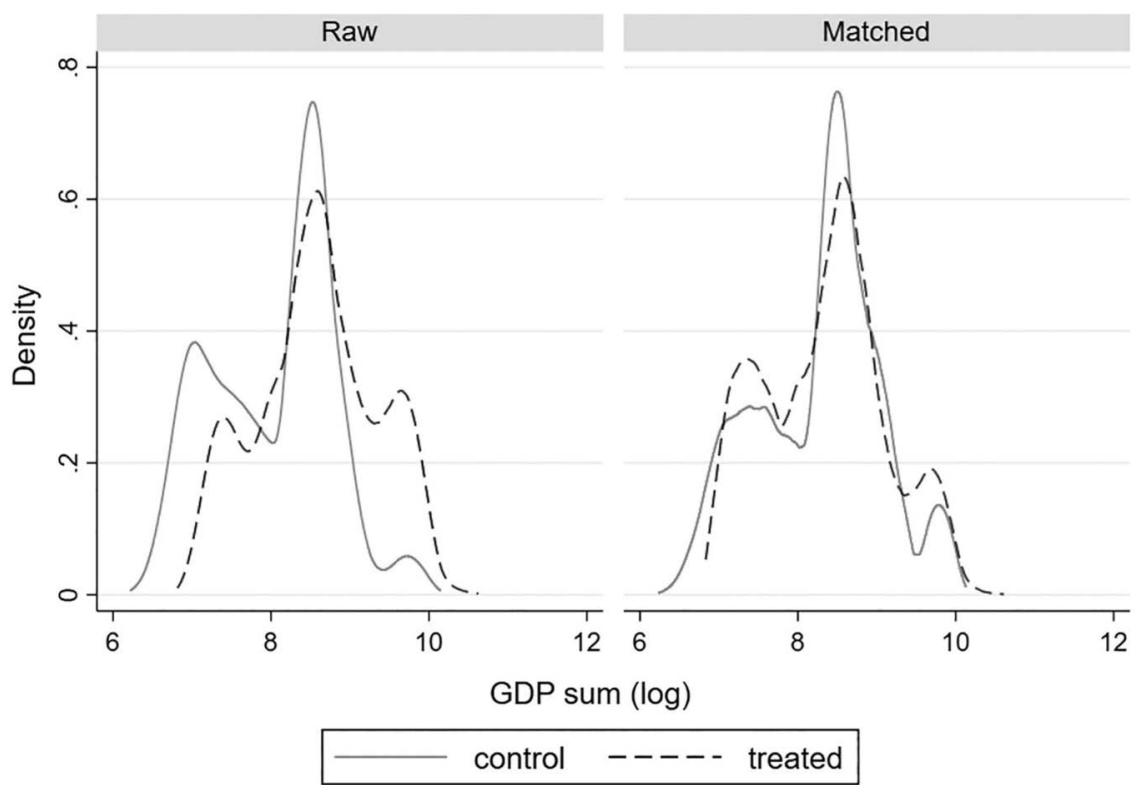

Figure 7.A-2a Balance plot of the sum of exporter and importer GDP: Wind.

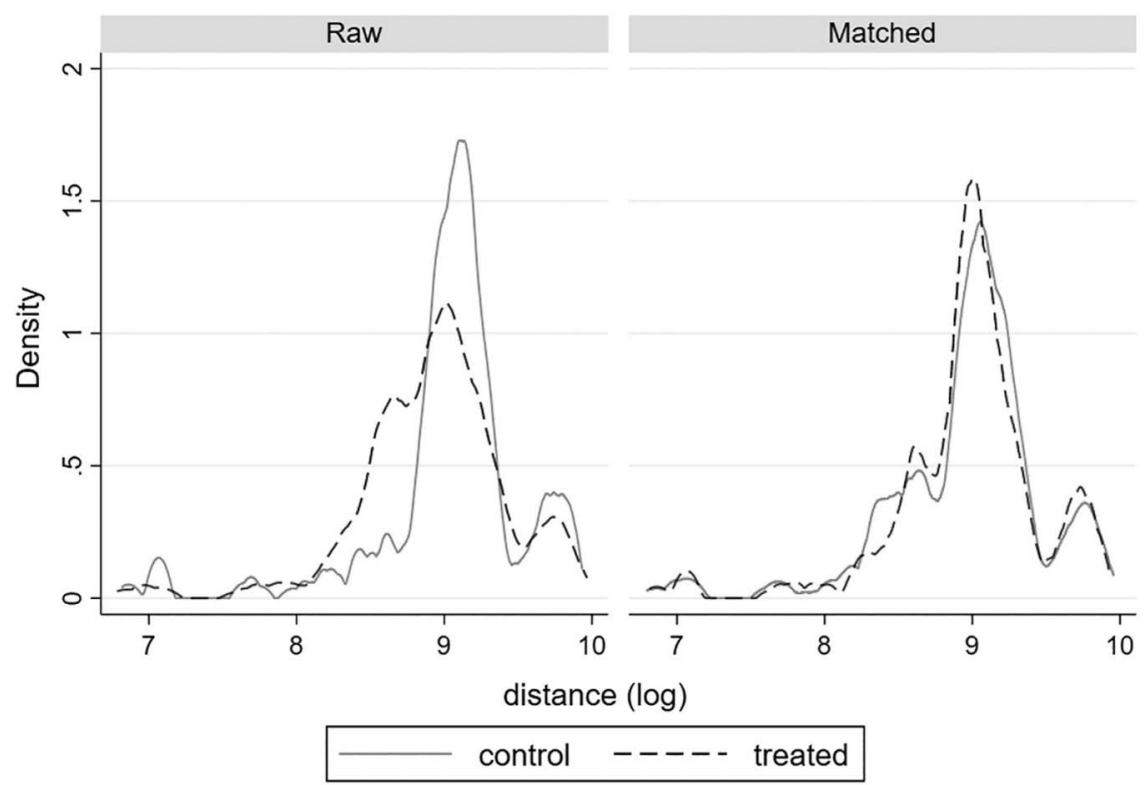

Figure 7.A-2b Balance plot of the distance between exporter and importer countries: Wind. 


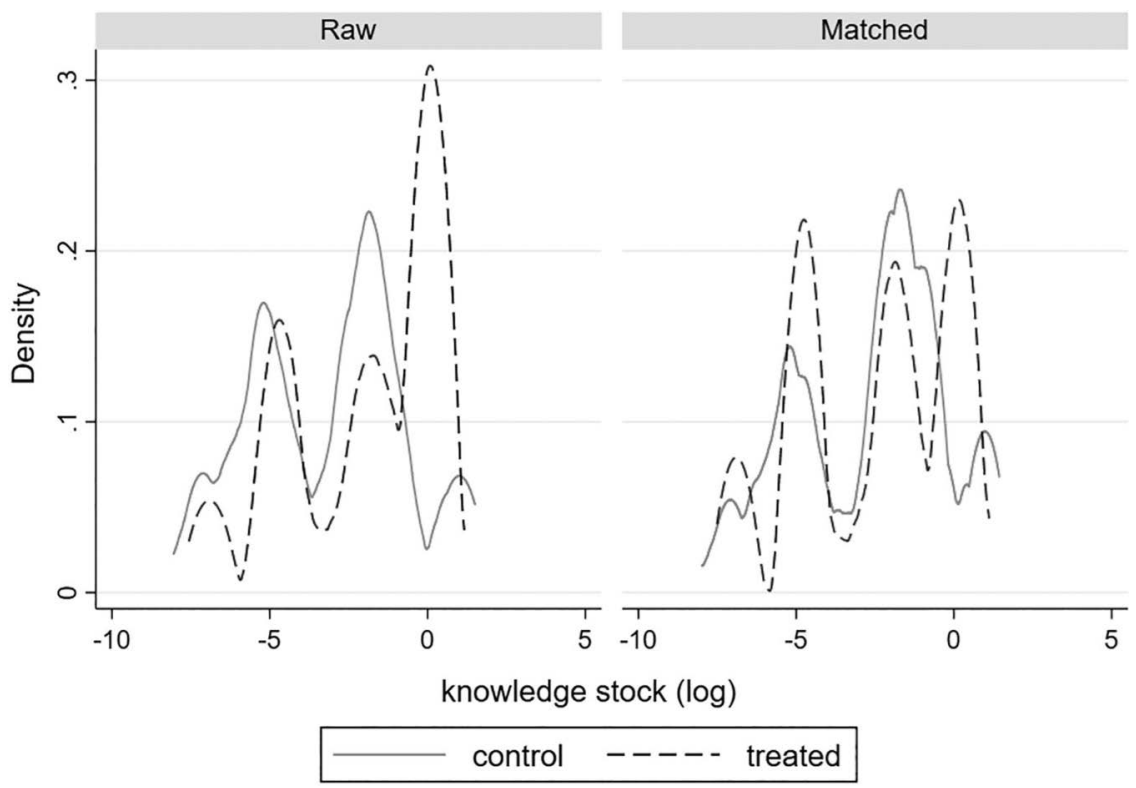

Figure 7.A-2c Balance plot of the exporter countries' knowledge stock: Wind.

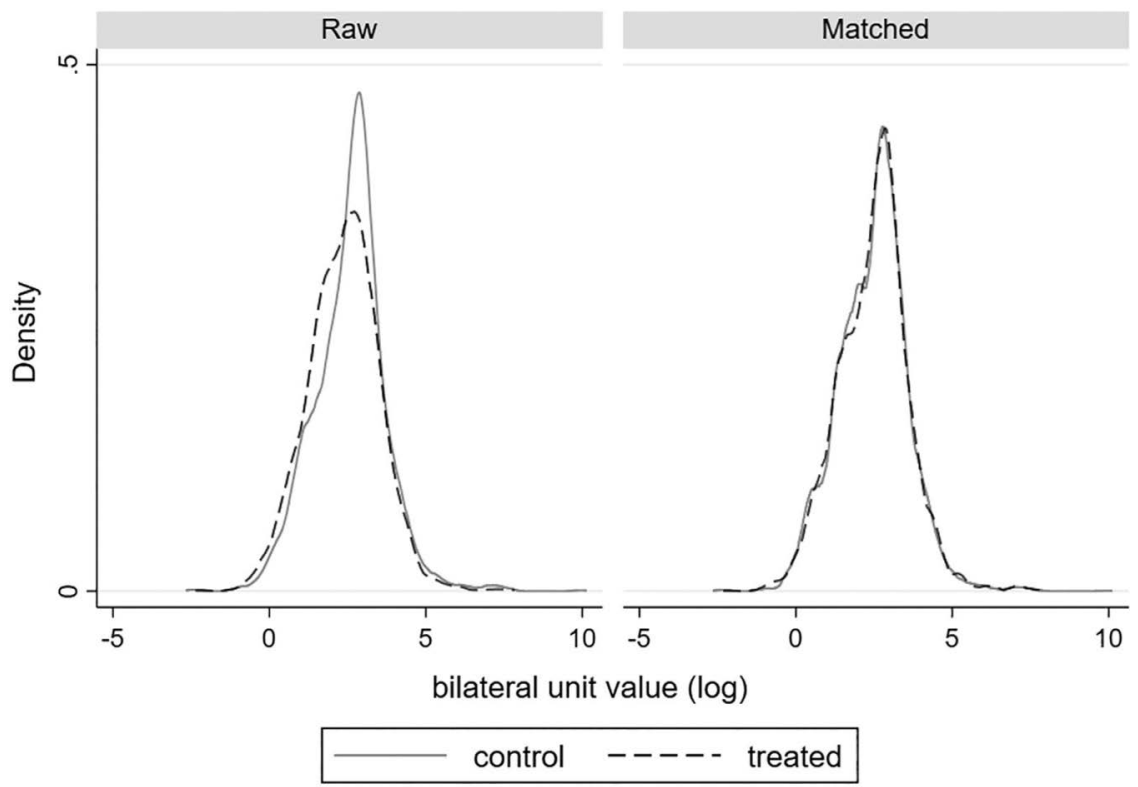

Figure 7.A-2d Balance plot of the bilateral unit value: Wind. 


\section{A.2 Complements}

Referring to Groba and Cao (2014), HS codes for PV and wind energy components are shown in Table 7.A.1.

The country list in this chapter is shown in Table 7.A.2. A total of 56 countries that were studied have been compiled in OECD-EPAU (2013) regarding the information on their renewable energy policy.

Summary statistics are shown in Table 7.A.3.

Table 7.A.1 HS codes of PV/wind energy components in this study

\begin{tabular}{ll}
\hline HS 1996 Code & Description \\
\hline $\begin{array}{l}\text { Solar photovoltaics } \\
850440\end{array}$ & \\
850720 & $\begin{array}{l}\text { Static converters } \\
854140\end{array}$ \\
& $\begin{array}{l}\text { Other lead-acid accumulators } \\
\text { Photosensitive semiconducter devices, including } \\
\text { photovoltaic cells whether or not assembled in } \\
\text { modules or made up into panels; light emitting diodes }\end{array}$ \\
& \\
Wind energy components \\
730820 & Towers and lattice masts \\
841290 & Parts of hydraulic/pneumatic/other power engines \\
841381 & Other pumps; liquid elevators - Pumps \\
850231 & Other generating sets - Wind-powered \\
850239 & Other generating sets - Other \\
850240 & Electric rotary converters
\end{tabular}

Source: Groba and Cao (2014)

Table 7.A.2 Classification of countries in this study

\begin{tabular}{lllll}
\hline Asian Countries & & & \\
\hline $\begin{array}{l}\text { China } \\
\text { India }\end{array}$ & Indonesia & South Korea & Thailand & \\
Others & Malaysia & & \\
Algeria & Czech Republic & Ireland & New Zealand & Spain \\
Argentina & Denmark & Iceland & Norway & Sweden \\
Australia & Egypt & Israel & Peru & Switzerland \\
Austria & Estonia & Italy & Poland & Tanzania \\
Belarus & Finland & Jordan & Portugal & Turkey \\
Belgium & France & Kenya & Russia & Uganda \\
Brazil & Germany & Latvia & Serbia & United Kingdom \\
Bulgaria & Greece & Mexico & Slovakia & United States \\
Canada & Hungary & Morocco & Slovenia & Urugyay \\
Chile & Iran & Netherlands & South Africa & \\
\hline
\end{tabular}


Table 7.A.3 Descriptive statistics

\begin{tabular}{lllllll}
\hline \multicolumn{1}{c}{$N$} & Mean & Std.Dev & Min. & Max. & Unit \\
\hline XPVijt & 6930 & 62.15 & 333.82 & 0 & 8820.50 & million USD \\
XWijt & 6930 & 7.291 & 36.17 & 0 & 946.38 & million USD \\
Yit & 6930 & 3330.61 & 3601.90 & 327.30 & 18559.25 & billion USD \\
Yjt & 6930 & 1215.24 & 2463.41 & 9.006 & 18559.25 & billion USD \\
Dij & 6930 & 9074.43 & 3694.90 & 955.65 & 19711.86 & km \\
CNTGij & 6930 & 0.018 & 0.134 & 0 & 1 & \\
LANGij & 6930 & 0.034 & 0.181 & 0 & 1 & \\
KPVit & 6930 & 515.35 & 1212.47 & 0 & 5535.58 & \\
KWit & 6930 & 178.52 & 370.22 & 0 & 1833.08 & \\
FiTPVit & 6930 & 0.444 & 0.497 & 0 & 1 & \\
FiTPVjt & 6930 & 0.457 & 0.498 & 0 & 1 & \\
FiTWit & 6930 & 0.413 & 0.492 & 0 & 1 & \\
FiTWjt & 6930 & 0.462 & 0.499 & 0 & 1 & \\
RPSit & 6930 & 0.183 & 0.386 & 0 & 1 & 1 \\
RPSjt & 6930 & 0.157 & 0.364 & 0 & 1 & \\
\hline
\end{tabular}

